\title{
Treatment of juvenile Graves' disease and its ophthalmic complication: the 'European way'
}

\author{
G E Krassas \\ Department of Endocrinology, Diabetes and Metabolism, Panagia General Hospital, Thessaloniki, Greece
}

(Correspondence should be addressed to G E Krassas, Associate Professor of Medicine, Chairman, Department of Endocrinology and Metabolism, Panagia General Hospital, Tsimiski 92, Thessaloniki, Greece 54622; Email: krassas@the.forthnet.gr)

\begin{abstract}
Three treatment modalities are available for Graves' disease: antithyroid drugs, surgery and radioactive iodine (RAI). None has been shown to be ideal or superior to the others. There are wide differences between individual physicians and between the physicians in different countries on the optional treatment for childhood hyperthyroidism. While antithyroid drugs remain the initial treatment of choice in almost all the medical centers in Europe, with surgery being used mainly to deal with antithyroid failures, radioiodine is preferred by only a small percentage of physicians for this group of patients. In the USA, on the contrary, radioiodine treatment of thyrotoxicosis in children has strong advocates, who emphasize the safety, simplicity and economic advantages of iodine-131 ablation, which should be considered more commonly in children. Until now, the available data have shown no significant increase in thyroid neoplasia, gonadal injury or congenital abnormalities in the offspring of older children and adults receiving RAI for thyrotoxicosis. Given the considerable increase in the risk of thyroid cancer in young children exposed to external radiation, it has been hypothesized that there may be a small increase in the risk of thyroid cancer in young children treated with RAI. Until long-term data on safety are available, specifically for young children, differences between the physicians in different countries will remain.
\end{abstract}

European Journal of Endocrinology 150 407-414

\section{Introduction}

The association of goiter and exophthalmos was first recorded in a Byzantine legal text from the third century, in which a 'man with bulging eyes and a great walnut round the neck' was described (1). The recognition of the disease known as exophthalmic goiter is attributed, however, to Parry, who, in 1786 , observed the first patient. However, his record of six cases was not published until 1825,3 years after his death (2, 3). Similar patients were reported in 1835 by Graves and in 1840 by Von Basedow $(2,4)$. Graves' disease (GD) is the most common cause of juvenile thyrotoxicosis in children and adolescents (5). In Denmark, about 95\% of children with thyrotoxicosis have GD $(5,6)$. In Iceland, the incidence of GD as a cause of thyrotoxicosis is $83 \%$ (7). Other causes of hyperthyroidism in this age group include thyroiditis (8), functioning thyroid adenoma or multinodular goiter (9), carcinoma (10), iodine-induced hyperthyroidism (11), thyrotropin-dependent hyperthyroidism (12) and excess ingestion of thyroid hormone (13). Overall, pediatric contribution to the incidence of thyrotoxicosis is small, the age group $0-15$ years contributing only $5-6 \%$ of the total number of patients (14). Most children with GD have a family history of some type of autoimmune thyroid disease (14), and some have other autoimmune endocrine diseases, such as diabetes mellitus and Addison's disease (15). Systemic lupus erythematosus, rheumatoid arthritis, myasthenia gravis, vitiligo, idiopathic thrombocytopenic purpura and pernicious anemia also have been described in these children (15). In addition, GD is more common in children with Down's syndrome than in normal children $(15,16)$.

\section{Clinical manifestations}

The main clinical features of thyrotoxicosis in children and adolescents, which are similar to those in adults, are shown in Table 1 (14, 17-19). Regarding ophthalmopathy, it appears that manifestations of thyroid eye disease in childhood thyrotoxicosis are more common but less severe, and more likely spontaneously to remit completely than in adults (20-24). Most children have stare and wide palpebral fissures, which are signs of thyrotoxicosis; 50-75\% have exophthalmos (25), 
Table 1 Clinical features of thyrotoxicosis in children and adolescents $(14,17-19)$.

\begin{tabular}{lc}
\hline & Percentage \\
\hline Goiter & 99 \\
Tachycardia & 83 \\
Nervousness & 80 \\
Increased pulse pressure & 77 \\
Hypertension & 71 \\
Exophthalmos & 66 \\
Tremor & 61 \\
Increased appetite & 60 \\
Weight loss & 54 \\
Thyroid bruit & 53 \\
Increased perspiration & 49 \\
Hyperactivity & 44 \\
Heart murmur & 43 \\
Palpitations & 34 \\
Heat intolerance & 33 \\
Fatigue & 16 \\
Headache & 15 \\
Diarrhea & 13 \\
\hline
\end{tabular}

which is occasionally asymmetric (23) but is rarely the presenting complaint (26). Eye pain, diplopia, chemosis and ophthalmoplegia are rare. The stare and wide palpebral fissures improve with treatment of thyrotoxicosis. As adolescence approaches, the manifestations of thyroid eye disease (TED) begin to simulate more closely the adult findings (23). Thyrotoxicosis associated with activating mutations of the thyroid-stimulating hormone (TSH) receptor has been associated with mild stare, lid retraction and the appearance of proptosis. It is presumed that these eye findings are the direct consequence of excessive thyroid hormone action, and that they are not immunologically mediated. The findings remit when the thyrotoxicosis is controlled (27-31).

\section{Treatment}

The ideal treatment of Graves' thyrotoxicosis in childhood remains controversial. None of the three available treatment modalities, antithyroid drugs (ATD), surgery and radioactive iodine (RAI), has been shown to be ideal or clearly superior to the others.

The ATD, methimazole (MMI), carbimazole (CMZ) and propylthiouracil (PTU), inhibit thyroid hormone biosynthesis (32). PTU has the additional property of inhibiting the extrathyroidal conversion of $\mathrm{T}_{4}$ to $\mathrm{T}_{3}$. CMZ is not available in the USA, but it is used extensively in Europe. MMI (and CMZ) has a longer serum half-life $(12-16 \mathrm{~h})(33,34)$, and therefore single daily doses are adequate in most patients. In contrast, PTU has a short half-life $(4-6 \mathrm{~h})$ and requires administration several times each day. However, it should be mentioned that all of the thionamide drugs are concentrated by the thyroid gland and therefore have a longer biologic half-life within the thyroid than in the blood. Moreover, some studies indicate that under certain circumstances PTU may be given once daily without losing control of hyperthyroidism (35). The recommended initial dose of MMI or CMZ is $0.5-1.0 \mathrm{mg} / \mathrm{kg}$ daily, given once or twice daily, and that of PTU is $5-10 \mathrm{mg} / \mathrm{kg}$ daily, given three times daily. Children who are older, with longer duration of symptoms, large goiters, or higher serum $\mathrm{T}_{4}$ and $\mathrm{T}_{3}$ concentrations, should be given the higher doses. Once the patient becomes euthyroid, the dose and frequency should be decreased. Occasionally, the dose needs to be increased because the initial dose was too small or the thyrotoxicosis has worsened. MMI (or CMZ) is preferable to PTU because single daily doses are effective in most patients, and fewer tablets per day are needed. The maximal clinical response to medications occurs after about 4-6 weeks of therapy. Before that time, the symptoms of hyperthyroidism may be controlled with beta-blockers such as propranolol (32-34). When clinical improvement occurs, the dose may be tapered in an attempt to maintain thyrohormone levels in the normal range. Two general methods are used. One method is to reduce the dose to achieve levels of $\mathrm{T}_{4}$ and $\mathrm{TSH}$ in the normal range. The advantage of this method is that the dosage, and therefore the side effects, may be minimized. Another method is to block and replace. This method may give more stable hormonal levels and optimize the probability of remission (36), although some authors dispute this proposition (37). Medical therapy has a high risk of failure in children with large goiters, a history of previous relapse, high thyroxine $(>20 \mu \mathrm{g} / \mathrm{dl})$ and thyroglobulin ( $>50 \mu \mathrm{g} / \mathrm{ml}$ ) levels, or ophthalmopathy (38). Remission rates range from $34 \%$ to $64 \%$ (Table 2) (39). Indicators of possible remission include a smaller size of the thyroid gland, a decreased $\mathrm{T}_{3}$ to $\mathrm{T}_{4}$ ratio, a

Table 2 Results of antithyroid drug treatment of children and adolescents with Graves' disease (adapted from 39).

\begin{tabular}{lccr}
\hline Reference & $\begin{array}{c}\text { No. of } \\
\text { patients }\end{array}$ & $\begin{array}{c}\text { Patients achieving } \\
\text { control initially (\%) }\end{array}$ & $\begin{array}{c}\text { Remission } \\
(\%)\end{array}$ \\
\hline Vaidya et al. (18) & 95 & 87 & 40 \\
Barnes et al. (17) & 104 & 100 & 13 \\
Maenpaa et al. (93) & 38 & 100 & 10 \\
Buckingham et al. (94) & 60 & 100 & 50 \\
Hamburger (73) & 182 & 87 & 34 \\
Lippe et al. (95) & 63 & 97 & 38 \\
Gorton et al. (96) & 53 & 98 & 36 \\
\hline
\end{tabular}


lower early radioiodine uptake and lower levels of TSH receptor antibodies $(40,41)$. Furthermore, when responses to medical therapy among prepubertal and pubertal children are compared, 1-year remission rates are considerably less in prepubertal $(17 \%)$ than in pubertal children (30\%) (42).

Major drawbacks to drug therapy are the failure to achieve remission, noncompliance, and toxicity. Concerning the latter, hepatic toxicity is a rare but potentially lethal complication of mainly PTU therapy. Eight deaths have been reported before 1999, but other cases obviously go unreported. There does not appear to be a dose-response relationship for PTU-induced hepatitis, with mean doses of $426 \mathrm{mg} /$ day (range $150-90 \mathrm{mg} /$ day). The average duration of therapy in the patients summarized by Williams et al. (43) was 3.6 months; however, in a recent report, severe hepatitis developed after 2 days of therapy (44), and in another case, hepatitis developed after 1 year of treatment (45). The mean age of all patients who developed hepatotoxicity was 28 years. In sharp contrast to the potentially lethal hepatocellular abnormalities seen with PTU, liver disease with methimazole is generally cholestatic in nature, and, until recently, there had never been a fatality reported in the literature. The complications of drug therapy are shown in Table 3 (39). When side effects of MMI or PTU develop, medication is often discontinued, and RAI or surgery is considered. Some clinicians will change to another thionamide when a mild toxic reaction occurs. However, published data about the risks and benefits of changing medications in children are limited (46). Medication changes should thus be made with caution. If a serious complication develops, such as hepatitis or agranulocytosis, it is best not to resume antithyroid drug therapy.

Surgery, specifically subtotal thyroidectomy, is the oldest form of therapy for GD. The Nobel Prize was awarded to Kocker in 1909 for innovations in this area. Thyroid surgery is often required for the treatment of childhood GD It is most often performed in patients with large goiters and severe thyrotoxicosis. Subtotal thyroidectomy is the most common procedure. The incidence of recurrent hyperthyroidism correlates with the size of the thyroid remnant. Experience has shown that when the thyroid remnant is less than $4 \mathrm{~g}$, the likelihood of recurrent thyrotoxicosis is small $(47,48)$. The likelihood of recurrence is even smaller after total thyroidectomy, but the morbidity rate is considerably higher. Preoperative therapy consists of Lugol's solution 10-14 days prior to surgery and beta-adrenegic blockers for the purpose of preventing thyroid storm. Like many others, it is our practice to employ ATD preoperatively. Postoperative complications in more than 2000 children and adolescents are summarized in Table 4 (49-55).

\section{Radioiodine therapy}

The thyroid gland is one of the most sensitive organs to the carcinogenic effects of radiation during childhood. While a number of studies have indicated a doseresponse effect, no clear threshold dose has been identified. Young age is a major factor for sensitivity to radiation. In the pooled analysis of seven studies, the risk of developing thyroid carcinoma after irradiation below the age of 5 years is twofold higher than in children treated with irradiation between 5 and 9 years of age, and fivefold higher than in children treated between 10 and 14 years of age (56). The high susceptibility of young children to the carcinogenic effects of radiation to the thyroid thus contrasts with the very low susceptibility of adults. This is consistent with experimental studies on animals and suggests greater radiation effects during periods of rapid cell proliferation, as observed during the development of the thyroid gland. The risk of thyroid cancer is not significant when individuals are over 15 or 20 years of age at exposure (57). RAI therapy for GD was introduced at Massachusetts General Hospital nearly 60 years ago $(58,59)$. It is estimated that more than 2 million patients of all ages have received RAI for GD, making this therapy one of the most widespread therapeutic uses of a systemically administered radionuclide (49). It has been proved to be an effective therapy for childhood thyrotoxicosis due to GD. It is the preferred treatment in some centers, especially in the USA, and in most others it is recommended for any patient who

Table 3 Complications of antithyroid drug treatment of children and adolescents with Graves' thyrotoxicosis (adopted from 39).

\begin{tabular}{|c|c|c|c|c|c|c|}
\hline \multirow[b]{2}{*}{ Reference } & \multirow[b]{2}{*}{$\begin{array}{c}\text { Poor compliance } \\
(\%)\end{array}$} & \multirow[b]{2}{*}{$\begin{array}{l}\text { Overall toxicity } \\
(\%)\end{array}$} & \multirow[b]{2}{*}{$\begin{array}{c}\text { Major toxicity* } \\
(\%)\end{array}$} & \multicolumn{2}{|c|}{ Minor toxicity } & \multirow[b]{2}{*}{$\begin{array}{c}\text { Hypothyroidism } \\
(\%)\end{array}$} \\
\hline & & & & $\begin{array}{l}\text { Rash } \\
(\%)\end{array}$ & $\begin{array}{l}\downarrow \text { WBC } \\
(\%)\end{array}$ & \\
\hline Vaidya et al. (18) & 17 & 5 & 0 & 1 & 3 & 8 \\
\hline Barnes et al. (17) & 16 & 14 & 6 & 8 & 1 & NR \\
\hline Shiroozu et al. (97) & 5 & 5 & 0 & 1.5 & 1.5 & 0 \\
\hline Buckingham et al. (94) & 7 & 32 & 14 & 7.5 & 9 & 6 \\
\hline Hamburger (73) & 9 & 17 & 6 & 8 & 3 & 5 \\
\hline Lippe et al. (95) & 2 & NR & 2 & NR & NR & NR \\
\hline Gorton et al. (96) & 13 & 11 & 4 & 7 & 2 & 11 \\
\hline
\end{tabular}

* Mainly severe polyarthritis, agranulocytocis, aplastic anemia, severe hepatitis and cholestasis. NR, non-reported. 
Table 4 Postoperative complications of thyroidectomy in more than 2000 children (49-55).

\begin{tabular}{lc}
\hline Complication & Incidence \\
\hline Pain & 100 \\
Transient hypocalcemia (1-7 days) & 10 \\
Keloid & 2.8 \\
Permanent hypoparathyroidism & 2 \\
Vocal cord paralysis & 2 \\
Transient hoarseness & 1 \\
Temporary tracheostomy & 0.7 \\
Hemorrhage/hematoma & 0.2 \\
Death & 0.08 \\
\hline
\end{tabular}

has a serious side effect or tires of ATD therapy. The dose in children, which is given orally, usually is calculated to deliver from 50 to $200 \mu \mathrm{Ci}(1.85-7.4 \mathrm{MBq})$ radioiodine per gram of thyroid tissue, estimated according to the following formula (60):

estimated thyroid weight (g) (by palpation or $\mathrm{U} / \mathrm{S}$ )

$$
\times 50 \text { to } 200 \mu \mathrm{Ci}{ }^{131} \mathrm{I}
$$

Younger children with smaller goiters usually are given lower doses, and those with larger goiters, higher doses. It is better to give more rather than less, because the likelihood of persistent thyrotoxicosis is lower. For example, in children treated with $50-100 \mu \mathrm{Ci} / \mathrm{g}$ thyroid tissue, $25-40 \%$ of patients are hyperthyroid several years after therapy (61). In comparison, in children treated with a single dose of $150-200 \mu \mathrm{Ci} / \mathrm{g}$ thyroid, hyperthyroidism persists in $5-20 \%$ of patients, and $60-90 \%$ of patients become hypothyroid $(60,62-64)$. The success of radioiodine therapy is influenced, apart from the size of the thyroid gland, by circulating levels of thyroid-stimulating antibodies (TSAb). Responses are lower in patients with high TSAb levels $(65,66)$. There is also some evidence that responses to radioiodine are less favorable after treatment with ATD $(67,68)$.

The major consequence of radioiodine therapy is hypothyroidism. It occurs in $20-40 \%$ of children in the first year after treatment and $2-3 \%$ per year thereafter; thus, most children eventually become hypothyroid (63). In a very recent study, Rivkees and Cornelius (69) examined the relationship between the dose of iodine-131 in children with hyperthyroidism and thyroid status 1 year after treatment. Three iodine-131 doses were compared: $72-108 \mathrm{~Gy}$ (80$120 \mu \mathrm{Ci} / \mathrm{g}), \quad 180-225 \mathrm{~Gy} \quad(200-250 \mu \mathrm{Ci} / \mathrm{g})$ and $270-364 \mathrm{~Gy}(300-405 \mu \mathrm{Ci} / \mathrm{g})$ in 31 patients ranging in age from 7 to 18 years. Thyroid status was assessed over 1 year after therapy. They found that doses of $100 \mathrm{~Gy}(110 \mu \mathrm{Ci} / \mathrm{g}), 200 \mathrm{~Gy}(220 \mu \mathrm{Ci} / \mathrm{g})$ and $300 \mathrm{~Gy}$ $(330 \mu \mathrm{Ci} / \mathrm{g})$ resulted in hypothyroidism in $50 \%, 70 \%$ and $95 \%$ of treated individuals respectively. They concluded that, to ensure ablation of thyroid tissue, doses over $270 \mathrm{~Gy}(300 \mu \mathrm{Ci} / \mathrm{g})$ are needed, especially when the thyroid is large. Another consequence seems to be the increased incidence of benign thyroid adenomas (70). This risk appeared to be higher in patients given lower doses of radioiodine. In the same study, thyroid carcinoma was no more common in radioiodine-treated patients than those treated with ATD or thyroidectomy (70). In a recent report, which is an update of reference 70, Ron et al. (71) observed, over a mean follow-up period that extended to 21 years, no increase in overall cancer mortality after iodine-131 therapy compared with standard US mortality rates. However, a small but statistically significant increase in thyroid cancer risk was found, which was more pronounced in patients with toxic nodular goiter. One explanation for the latter observation may be that thyroid glands affected by GD are more likely to be totally destroyed by iodine131 than would large multinodular thyroid glands. The remaining irradiated tissue would then be at risk of subsequent neoplastic transformation. Although none of the thyroid cancer deaths occurred in individuals who where treated as children, the number of treated children was very small, and the thyroid cancer incidence in this group is unknown (71). In general, outcomes after iodine-131 treatment for juvenile hyperthyroidism have been reported so far for approximately 1000 individuals in different reports $(19,62,63,72-76)$. The duration of follow-up in those studies ranged from less than 5 years to 15 years, with only some subjects followed for more than 20 years. These studies have not revealed an increased risk of thyroid malignancy, as stated by Rivkees et al. (49). Only four cases of thyroid malignancy in children previously treated with iodine-131 have been reported so far $(19,61,77,78)$. Three of these individuals were treated with low doses of iodine131, and one patient with a moderate one. As discussed above, low doses of iodine-131 are associated with an increased incidence of thyroid nodules and neoplasms (78). A significant relationship between the number of iodine-131 treatments and thyroid cancer was also reported by Ron et al. (71), in a study which mainly concerns adult patients with thyrotoxicosis. This finding justifies those who advocate that when RAI is used in children, it is important that a higher dose of iodine-131 is given. The goal of RAI therapy from the beginning in such cases should be to ablate the thyroid gland and achieve hypothyroidism. If no thyroid tissue remains, the risk of thyroid cancer will be very small, if present at all. To achieve this goal, Rivkees used doses of iodine-131 of 250$300 \mu \mathrm{Ci} / \mathrm{g}$ thyroid tissue (79). Another potential adverse effect of RAI therapy is the development or worsening of ophthalmopathy, as has been observed in adults $(80,81)$. However, no such data have been reported so far in a pediatric group. 


\section{Thyroid eye disease in childhood}

In contrast to adults, as stated above, ophthalmopathy in childhood thyrotoxicosis is more common but less severe, and more likely to remit completely. It is well known that exophthalmometry varies in different population studies and is age-related. A study conducted by Gerber et al. (82) to determine the normal standards for exophthalmometry in children 10-14 years of age, in relation to age, height, weight and sexual maturation, found that the mean measurement for boys is of the order of 17.0 and ranges from 16.3 to $18.0 \mathrm{~mm}$, while for girls it is 16.8 and ranges from 16.7 to $17.6 \mathrm{~mm}$. In a series of 87 children treated with iodine-131 for GD, Safa et al. (63) reported that eye signs improved in $90 \%$ of the children, did not change in $7.5 \%$ and worsened in 3\% after treatment. Gruters (21) found among 43 child patients with hyperthyroidism that $37 \%$ had upper lid retraction, lid lag or proptosis, but only three of the group had soft tissue involvement and significant exophthalmos. None required specific treatment. In the study of Young (22), only one of 33 patients seen required a course of steroid therapy, and none were offered orbital decompression or radiotherapy. Uretsky et al. (23) noted that in 34 patients with childhood GD no instances of sight-threatening complications were noted, and only three patients showed evidence of ophthalmoplegia. Liu et al. (24) described two patients who had surgical removal of orbital fat for severe proptosis. Finally, in a recent Chinese study, Chan et al. (83) investigated 83 patients with GD aged 16 years or below. A comprehensive ophthalmic assessment, including ocular motility, exophthalmometry, intraocular pressure, slit lamp and fundus examinations, was performed. A total of 52 patients $(62.7 \%)$ were identified with positive ocular changes. However, none had visually threatening complications or debilitating myopathy. In a recent study of eight children aged 4-14 years, none had deterioration of eye disease after RAI therapy (84). The expectation remains, however, that the expression of Graves' ophthalmopathy in children is, in most instances, both mild and transient. Steroids and decompression will very rarely be needed in early childhood. It has to be kept in mind that prolonged prednisone administration, which should be used in some severe cases of TED, is associated with weight gain, immune suppression and growth failure in children (49).

Recent studies have shown successful therapy with the long-acting somatostatin analogs (SM-a), octreotide and lanreotide in adult patients with active TED $(85-87)$. The rationale of this therapy is based on recent studies in which somatostatin receptors have been identified within the orbital tissues in TED, both in vitro and in vivo $(88-90)$.

We recently had the opportunity to treat three adolescents (two girls and one boy) aged 14, 15 and
16 years, with moderately severe TED, with SM-a. The results of the first two have been presented previously (91). All had increased clinical activity scores (CAS) $-4,5$ and 6 respectively. All were on antithyroid therapy and euthyroid at the time of initiation of treatment. They received $20 \mathrm{mg}$ octreotide (sandostatinLAR) i.m., one injection every 30 days for 4 months. Their ophthalmopathy improved substantially, and CAS decreased in all patients. In view of the encouraging therapeutic results in these three pediatric patients, SM-a may prove to be a valuable treatment in childhood ophthalmopathy and a good alternative to corticosteroids. The results using SM-a in the treatment of TED seem promising, but it is still premature to suggest this therapeutic option, without any prospective, double-blind controlled study.

In summary, there are wide differences between individual physicians and between the physicians in different countries on the optional treatment for childhood hyperthyroidism. While ATD remains the initial treatment of choice in almost all the medical centers in Europe, surgery being used mainly to deal with antithyroid failures, there is increasing interest in the use of radioiodine especially in the USA. A European questionnaire study (92), which was conducted by the European Thyroid Association (ETA) in 1993, and in which 99 individuals or groups from 22 countries participated, found that 22 out 99 physicians from nine countries would consider radioiodine treatment as the treatment of choice for children with recurrent thyrotoxicosis after surgery, or with recurrent thyrotoxicosis 2 years after ATD. However, radioiodine was preferred by only a small percentage of physicians for this group of patients in Europe. Hardly any of the respondents chose radioiodine for the patients with a toxic adenoma or a multinodular, toxic goiter (92). In view of the difficulties with medical therapy in children and adolescents, including poor compliance, high rate of relapse, drug toxicity, and continued thyroid enlargement, eminent US physicians emphasize the safety, simplicity and economic advantages of iodine-131 ablation, which should be considered more commonly in children (60). Although there are data showing no significant increase in thyroid neoplasia, gonadal injury or congenital abnormalities in the offspring of older children and adults receiving outpatient doses of radioiodine, endocrinologists and parents continue to shy away from this therapy in young children, especially in Europe. Given the considerable increase in the risk of thyroid cancer in young children exposed to external radiation, it has been hypothesized that there may be a small increase in the risk of thyroid cancer in young children treated with radioiodine. This theoretical risk is probably highest in children before the age of 5 years and progressively lower in those treated at 5-10 and $10-20$ years (49). Until long-term data on safety are available, specifically for young children, differences between the physicians in 
different countries concerning the optimum therapy of childhood GD will remain.

\section{References}

1 Marketos SG, Eftychiadis A \& Koutras DA. The first recognition of the association between goiter and exophthalmos. Journal of Endocrinological Investigation $19836401-403$.

2 Drury MI. Robert Graves - 150 years ago. Irish Medical Science 1985154 470-471.

3 Parry C. Collections from the Unpublished Medical Writings, vol 2 p 111. London: Underwoods, 1825.

4 Graves RJ. Newly observed affection of the thyroid gland in females. In Classic Descriptions of Disease: With Biographical Sketches of the Authors, p 280. Ed. RH Major. Springfield, IL: Charles Thomas, 1945.

5 Foley TP Jr. Thyrotoxicosis in childhood. Pediatric Annals 199221 43-46, 48-49.

6 Lavard L, Ranlov I, Perrild H, Andersen O \& Jacobsen BB. Incidence of juvenile thyrotoxicosis in Denmark, 1982-1988. A nationwide study. European Journal of Endocrinology 1994130 565-568.

7 Haraldsson A, Gudmundsson ST, Larusson G \& Sigurdsson G. Thyrotoxicosis in Iceland 1980-1982. An epidemiological survey. Acta Medica Scandinavica 1985217 253-258.

8 Sato T, Takata I, Taketani T, Saida K \& Nakajima H. Concurrence of Graves' disease and Hashimoto's thyroiditis. Archives of Disease in Childhood 197752 951-955.

9 Abe K, Konno M, Sato T \& Matsuura N. Hyperfunctioning thyroid nodules in children. American Journal of Diseases of Children 1980 $134961-963$.

10 Sussman L, Librik L \& Clayton GW. Hyperthyroidism attributable to a hyperfunctioning thyroid carcinoma. Journal of Pediatrics $196872208-213$.

11 Fradkin JE \& Wolff J. Iodide-induced thyrotoxicosis. Medicine 1983 $621-20$.

12 Weintraub BD, Gershengorn MC, Kourides IA \& Fein H. Inappropriate secretion of thyroid-stimulating hormone. Annals of Internal Medicine 198195 339-351.

13 Gorman CA, Wahner HW \& Tauxe WN. Metabolic malingerers. Patients who deliberately induce or perpetuate a hypermetabolic or hypometabolic state. American Journal of Medicine $1970 \mathbf{4 8}$ $708-714$.

14 Saxena KM, Crawford JD \& Talbot NB. Childhood thyrotoxicosis: a long-term perspective. British Medical Journal 19642 1153-1158.

15 Friedman JM \& Fialkow PJ. The genetics of Graves' disease. Clinics in Endocrinology and Metabolism 1978 7 47-65.

16 Zakarija M, McKenzie JM \& Hoffman WH. Prediction and therapy of intrauterine and late-onset neonatal hyperthyroidism. Journal of Clinical Endocrinology and Metabolism $1986 \mathbf{6 2} 368-371$.

17 Barnes HV \& Blizzard RM. Antithyroid drug therapy for toxic diffuse goiter (Graves' disease): thirty years' experience in children and adolescents. Journal of Pediatrics 197791 313-320.

18 Vaidya VA, Bongiovanni AM, Parks JS, Tenore A \& Kirkland RT. Twenty-two years' experience in the medical management of juvenile thyrotoxicosis. Pediatrics 197454 565-570.

19 Kogut MD, Kaplan SA, Collip PJ, Tiamsic T \& Boyle D. Treatment of hyperthyroidism in children. New England Journal of Medicine 1965272 217-221.

20 Inada M, Nishikawa M, Naito K, Ishii H, Tanaka K, Mashio Yet al. Sex- and age-related changes of exophthalmos in Graves' disease. Endocrinologica Japonica 198128 515-519.

21 Gruters A. Ocular manifestations in children and adolescents with thyrotoxicosis. Experimental and Clinical Endocrinology and Diabetes 1999107 (Suppl 5) S172-S174.

22 Young LA. Dysthyroid ophthalmopathy in children. Journal of Pediatric Ophthalmology and Strabismus 197916 105-107.
23 Uretsky SH, Kennerdell JS \& Gutai JP. Graves' ophthalmopathy in childhood and adolescence. Archives of Ophthalmology 198098 1963-1964.

24 Liu GT, Heher KL, Katowitz JA, Kazim M, Moazami G, Moshang T et al. Prominent proptosis in childhood thyroid eye disease. Ophthalmology $1996 \mathbf{1 0 3} 779-784$.

25 Bahn RS \& Heufelder AE. Pathogenesis of Graves' ophthalmopathy. New England Journal of Medicine 1993329 1468-1475.

26 Gorman CA. Temporal relationship between onset of Graves' ophthalmopathy and diagnosis of thyrotoxicosis. Mayo Clinic Proceedings $1983 \mathbf{5 8} 515-519$.

27 Gruters A, Schoneberg T, Biebermann H, Krude H, Krohn HP, Dralle $\mathrm{H}$ et al. Severe congenital hyperthyroidism caused by a germ-line neomutation in the extracellular portion of the thyrotropin receptor. Journal of Clinical Endocrinology and Metabolism $1998831431-1436$.

28 Holzapfel HP, Wonerow P, von Petrykowski W, Henschen M, Scherbaum WA \& Paschke R. Sporadic congenital hyperthyroidism due to a spontaneous germline mutation in the thyrotropin receptor gene. Journal of Clinical Endocrinology and Metabolism 199782 3879-3884.

29 Kopp P, van Sande J, Parma J, Duprez L, Gerber H, Joss E et al. Brief report: congenital hyperthyroidism caused by a mutation in the thyrotropin-receptor gene. New England Journal of Medicine 1995 332 150-154.

30 Kopp P, Muirhead S, Jourdain N, Gu WX, Jameson JL \& Rodd C. Congenital hyperthyroidism caused by a solitary toxic adenoma harboring a novel somatic mutation (serine $281->$ isoleucine) in the extracellular domain of the thyrotropin receptor. Journal of Clinical Investigation $1997 \mathbf{1 0 0} 1634-1639$.

31 Lavard L, Sehested A, Brock Jacobsen B, Muller J, Perrild H, Feldt-Rasmussen $U$ et al. Long-term follow-up of an infant with thyrotoxicosis due to germline mutation of the TSH receptor gene (Met453Thr). Hormone Research 1999 51 43-46.

32 Cooper DS. Antithyroid drugs for the treatment of hyperthyroidism caused by Graves' disease. Endocrinology and Metabolism Clinics of North America 198927225.

33 Cooper DS. Which anti-thyroid drug? American Journal of Medicine $1986801165-1168$.

34 Cooper DS. Antithyroid drugs. New England Journal of Medicine $19843111353-1362$.

35 Greer MA, Meihoff WC \& Studer H. Treatment of hyperthyroidism with a single daily dose of propylthiouracil. New England Journal of Medicine $1965272888-891$.

36 Hashizume K, Ichikawa K, Sakurai A, Suzuki S, Takeda T, Kobayashi $\mathrm{M}$ et al. Administration of thyroxine in treated Graves' disease. Effects on the level of antibodies to thyroid-stimulating hormone receptors and on the risk of recurrence of hyperthyroidism. New England Journal of Medicine 1991324 947-953.

37 McIver B, Rae P, Beckett G, Wilkinson E, Gold A \& Toft A. Lack of effect of thyroxine in patients with Graves' hyperthyroidism who are treated with an antithyroid drug. New England Journal of Medicine $1996334220-224$.

38 Tan SH, Lee BW, Wong HB \& Uma R. Relapse markers in childhood thyrotoxicosis. Clinical Pediatrics 198726 136-139.

39 La Franchi S \& Hanna CE. Graves' disease in the neonatal period and childhood. In Werner and Ingbar's The Thyroid. A Fundamental and Clinical Text, 8th edn, pp 989-997. Eds LE Braverman \& RD Utiger. New York: Lippincott, 2000.

40 Foley TP Jr, White C \& New A. Juvenile Graves' disease: usefulness and limitations of thyrotropin receptor antibody determinations. Journal of Pediatrics $1987110378-386$.

41 Rees Smith B, McLachlan SM \& Furmaniak J. Autoantibodies to the thyrotropin receptor. Endocrine Reviews 19889 106-121.

42 Shulman DI, Muhar I, Jorgensen EV, Diamond FB, Bercu BB \& Root AW. Autoimmune hyperthyroidism in prepubertal children and adolescents: comparison of clinical and biochemical features at diagnosis and responses to medical therapy. Thyroid 19977 $755-760$ 
43 Williams KV, Nayak S, Becker D, Reyes J \& Burmeister LA. Fifty years of experience with propylthiouracil-associated hepatotoxicity: what have we learned? Journal of Clinical Endocrinology and Metabolism 199782 1727-1733.

44 Hardee JT, Barnett AL, Thannoun A, Eghtesad B, Wheeler D \& Jamal MM. Propylthiouracil-induced hepatotoxicity. Western Journal of Medicine $1996 \mathbf{1 6 5} 144-147$.

45 Limaye A \& Ruffolo PR. Propylthiouracil-induced fatal hepatic necrosis. American Journal of Gastroenterology 198782 152-154.

46 Lazar L, Kalter-Leibovici O, Pertzelan A, Weintrob N, Josefsberg Z \& Phillip M. Thyrotoxicosis in prepubertal children compared with pubertal and postpubertal patients. Journal of Clinical Endocrinology and Metabolism $2000 \mathbf{8 5} 3678-3682$.

47 Andrassy RJ, Buckingham BA \& Weitzman JJ. Thyroidectomy for hyperthyroidism in children. Journal of Pediatric Surgery 198015 501-504.

48 Hayles AB, Chaves-Carballo E \& McConahey WM. The treatment of hyperthyroidism (Graves' disease) in children. Mayo Clinic Proceedings $1967 \mathbf{4 2} 218-224$.

49 Rivkees SA, Sklar C \& Freemark M. Clinical review 99: the management of Graves' disease in children, with special emphasis on radioiodine treatment. Journal of Clinical Endocrinology and Metabolism $1998 \mathbf{8 3} 3767-3776$.

50 Foster RS Jr. Morbidity and mortality after thyroidectomy. Surgery, Gynecology and Obstetrics $1978 \mathbf{1 4 6} 423-429$.

51 Buckingham BA, Costin G, Roe TF, Weitzman JJ \& Kogut MD. Hyperthyroidism in children. A reevaluation of treatment. American Journal of Diseases of Children 1981135 112-117.

52 Ching T, Warden MJ \& Fefferman RA. Thyroid surgery in children and teenagers. Archives of Otolaryngology $1977 \mathbf{1 0 3} 544-546$.

53 Miccoli P, Vitti P, Rago T, Iacconi P, Bartalena L, Bogazzi F et al. Surgical treatment of Graves' disease: subtotal or total thyroidectomy? Surgery $1996 \mathbf{1 2 0} 1020-1024$.

54 Perzik SL. Total thyroidectomy in Graves' disease in children. Journal of Pediatric Surgery 197611 191-194.

55 Thompson NW, Dunn EL, Freitas JE, Sisson JC, Coran AG \& Nishiyama RH. Surgical treatment of thyrotoxicosis in children and adolescents. Journal of Pediatric Surgery $1977 \quad 12$ 1009-1018.

56 Ron E, Lubin JH, Shore RE, Mabuchi K, Modan B, Pottern LM et al. Thyroid cancer after exposure to external radiation: a pooled analysis of seven studies. Radiation Research $1995 \mathbf{1 4 1} 259-277$.

57 Schlumberger M \& Pacini F. Thyroid tumors after external irradiation to the neck. In Thyroid Tumors, pp 243-255. Eds M Schlumberger \& F Pacini. Paris: Nucleon, 2003.

58 Becker DV \& Sawin CT. Radioiodine and thyroid disease: the beginning. Seminars in Nuclear Medicine 199626 155-164.

59 Chapman EM. History of the discovery and early use of radioactive iodine. Journal of the American Medical Association 1983250 2042-2044.

60 Levy WJ, Schumacher OP \& Gupta M. Treatment of childhood Graves' disease. A review with emphasis on radioiodine treatment. Cleveland Clinic Journal of Medicine 198855 373-382.

61 Sheline GE, Lindsay S, McCormack KR \& Galante M. Thyroid nodules occurring late after treatment of thyrotoxicosis with radioiodine. Journal of Clinical Endocrinology and Metabolism $1962228-17$.

62 Hayek A, Chapman EM \& Crawford JD. Long-term results of treatment of thyrotoxicosis in children and adolescents with radioactive iodine. New England Journal of Medicine $1970 \mathbf{2 8 3}$ 949-953.

63 Safa AM, Schumacher OP \& Rodriguez-Antunez A. Long-term follow-up results in children and adolescents treated with radioactive iodine $\left({ }^{131} \mathrm{I}\right)$ for hyperthyroidism. New England Journal of Medicine 1975292 167-171.

64 Snyder S. Vocal cord paralysis after radioiodine therapy. Journal of Nuclear Medicine $197819975-976$.

65 Chiovato L, Fiore E, Vitti P, Rocchi R, Rago T, Dokic D et al. Outcome of thyroid function in Graves' patients treated with radioiodine: role of thyroid-stimulating and thyrotropin-blocking antibodies and of radioiodine-induced thyroid damage. Journal of Clinical Endocrinology and Metabolism 199883 40-46.

66 Murakami Y, Takamatsu J, Sakane S, Kuma K \& Ohsawa N. Changes in thyroid volume in response to radioactive iodine for Graves' hyperthyroidism correlated with activity of thyroid-stimulating antibody and treatment outcome. Journal of Clinical Endocrinology and Metabolism 199681 3257-3260.

67 Hancock LD, Tuttle RM, LeMar H, Bauman J \& Patience T. The effect of propylthiouracil on subsequent radioactive iodine therapy in Graves' disease. Clinical Endocrinology $1997 \mathbf{4 7}$ 425-430.

68 Yoshida K, Aizawa Y, Kaise N, Fukazawa H, Kiso Y, Sayama N et al. Relationship between thyroid-stimulating antibodies and thyrotropin-binding inhibitory immunoglobulins years after administration of radioiodine for Graves' disease: retrospective clinical survey. Journal of Endocrinological Investigation $1996 \quad 19$ $682-686$.

69 Rivkees SA \& Cornelius EA. Influence of iodine-131 dose on the outcome of hyperthyroidism in children. Pediatrics $2003 \mathbf{1 1 1}$ 745-749.

70 Dobyns BM, Sheline GE, Workman JB, Tompkins EA, McConahey WM \& Becker DV. Malignant and benign neoplasms of the thyroid in patients treated for hyperthyroidism: a report of the cooperative thyrotoxicosis therapy follow-up study. Journal of Clinical Endocrinology and Metabolism 197438 976-998.

71 Ron E, Doody MM, Becker DV, Brill AB, Curtis RE, Goldman MB et al. Cancer mortality following treatment for adult hyperthyroidism. Cooperative Thyrotoxicosis Therapy Follow-up Study Group. Journal of American Medical Association $1998 \mathbf{2 8 0} 347-355$.

72 Freitas JE, Swanson DP, Gross MD \& Sisson JC. Iodine-131: optimal therapy for hyperthyroidism in children and adolescents? Journal of Nuclear Medicine 197920 847-850.

73 Hamburger JI. Management of hyperthyroidism in children and adolescents. Journal of Clinical Endocrinology and Metabolism $1985601019-1024$.

74 Zimmerman D \& Lteif AN. Thyrotoxicosis in children. Endocrinology and Metabolism Clinics of North America 199827 109-126.

75 Clark JD, Gelfand MJ \& Elgazzar AH. Iodine-131 therapy of hyperthyroidism in pediatric patients. Journal of Nuclear Medicine $199536442-445$.

76 Starr P, Jaffe HL \& Oettinger L Jr. Later results of 131-I treatment of hyperthyroidism in 73 children and adolescents: 1967 followup. Journal of Nuclear Medicine 196910 586-590.

77 Farbota LM, Calandra DB, Lawrence AM \& Paloyan E. Thyroid carcinoma in Graves' disease. Surgery 198598 1148-1153.

78 Gorman CA \& Robertson JS. Radiation dose in the selection of 131I or surgical treatment for toxic thyroid adenoma. Annals of Internal Medicine $1978 \mathbf{8 9} 85-90$.

79 Rivkees SA. The management of hyperthyroidism in children with emphasis on the use of radioactive iodine. Pediatric Endocrine Reviews 20041 (Suppl 1) 212-221.

80 Tallstedt L, Lundell G, Torring O, Wallin G, Ljunggren JG, Blomgren $\mathrm{H}$ et al. Occurrence of ophthalmopathy after treatment for Graves' hyperthyroidism. The Thyroid Study Group. New England Journal of Medicine 1992326 1733-1738.

81 Bartlena L, Marcocci C, Bogazzi F, Manetti L, Tanda ML, Dell'Unto E et al. Relation between therapy for hyperthyroidism and the course of Graves' ophthalmopathy. New England Journal of Medicine $199833873-78$.

82 Gerber FR, Taylor FH, deLevie M, Drash AL \& Kenny FM. Normal standards for exophthalmometry in children 10 to 14 years of age: relation to age, height, weight, and sexual maturation. Journal of Pediatrics $1972 \mathbf{8 1} 327-329$.

83 Chan W, Wong GW, Fan DS, Cheng AC, Lam DS \& Ng JS. Ophthalmopathy in childhood Graves' disease. British Journal of Ophthalmology $200286740-742$.

84 Cheetham TD, Wraight P, Hughes IA \& Barnes ND. Radioiodine treatment of Graves' disease in young people. Hormone Research $199849258-262$. 
85 Krassas GE. Somatostatin analogues in the treatment of thyroid eye disease. Thyroid $1998 \mathbf{8} 443-445$.

86 Krassas GE, Dumas A, Pontikides N \& Kaltsas T. Somatostatin receptor scintigraphy and octreotide treatment in patients with thyroid eye disease. Clinical Endocrinology 199542 571-580.

87 Krassas GE, Kaltsas T, Dumas A, Pontikides N \& Tolis G. Lanreotide in the treatment of patients with thyroid eye disease. European Journal of Endocrinology 1997136 416-422.

88 Krassas GE \& Kahaly GJ. The role of octreoscan in thyroid eye disease. European Journal of Endocrinology 1999140 373-375.

89 Pasquali D. Somatostatin receptor genes are expressed in lymphocytes from retroorbital tissues in Graves' disease. Journal of Clinical Endocrinology and Metabolism 200287 5125-5129.

90 Pasquali D, Vassallo P, Esposito D, Bonavolonta G, Bellastella A \& Sinisi AA. Somatostatin receptor gene expression and inhibitory effects of octreotide on primary cultures of orbital fibroblasts from Graves' ophthalmopathy. Journal of Molecular Endocrinology 200025 63-71.

91 Krassas GE. Thyroid eye disease in children and adolescents new therapeutic approaches. Journal of Pediatric Endocrinology and Metabolism 2001 14 97-100.

92 Perrild H, Gruters-Kieslich A, Feldt-Rasmussen U, Grant D, Martino E, Kayser L et al. Diagnosis and treatment of thyrotoxicosis in childhood. A European questionnaire study. European Journal of Endocrinology 1994131 467-473.

93 Maenpaa J \& Kuusi A. Childhood hyperthyroidism. Results of treatment. Acta Paediatrica Scandinavica 198069 137-142.

94 Buckingham BA, Costin G, Roe TF, Weitzman JJ \& Kogut MD. Hyperthyroidism in children. A reevaluation of treatment. American Journal of Diseases of Children $1981135112-117$.

95 Lippe BM, Landaw EM \& Kaplan SA. Hyperthyroidism in children treated with long-term medical therapy: twenty-five percent remission every two years. Journal of Clinical Endocrinology and Metabolism 198764 1241-1245.

96 Gorton C, Sadeghi-Nejad A \& Senior B. Remission in children with hyperthyroidism treated with propylthiouracil. Long-term results. American Journal of Diseases of Children 1987141 1084-1086.

97 Shiroozu A, Okamura K, Ikenoue H, Sato K, Nakashima T, Yoshinari M et al. Treatment of hyperthyroidism with a small single daily dose of methimazole. Journal of Clinical Endocrinology and Metabolism $1986 \mathbf{6 3} 125-128$.

Received 29 August 2003

Accepted 7 January 2004 